\title{
Aortic thrombosis in the newborn period
}

\author{
G. T. KNOWLSON AND H. B. MARSDEN
}

From the Department of Pathology, University of Manchester, and Royal Manchester Children's Hospital

SUMMARY Three cases are reported in which thrombi were found in the aorta at postmortem. In each case the thrombus had originated within the ductus arteriosus. We believe that in recent years the attention paid to the presence of indwelling cannulae as a cause of embolic phenomena in the newborn period has led to a reduction in emphasis on the importance of the ductus in this field. We think that the ductus should still be regarded as an important source of some emboli.

Arterial embolic phenomena in the newborn are a relatively rare occurrence. The usual mode of presentation is that of gangrene in one or several limbs, but there is evidence to show that thrombosis can occur in any artery in the body (Dohan, 1934). In recent years several theories have been put forward but the dominant ones have implicated the ductus arteriosus and the presence of indwelling cannulae. Before 1940 emphasis was laid on abnormal birth trauma and sepsis; it was only relatively recently that Gross (1945) re-emphasised the importance of the closure of the ductus in this condition. We report 3 cases of thrombosis in the aorta in which the thrombi originated in the ductus.

\section{Case reports}

Case 1. A male infant was first admitted to hospital at the age of 3 days with a feeding problem and was discharged a few days later after observation. At 16 days he was readmitted because of failure to gain weight and loose stools. There was no significant family history and no history of maternal diabetes. On admission there was marked dehydration with signs of peripheral circulatory failure. Blood pressure was $50 / ? \mathrm{mmHg}$, respiration rate $80 /$ minute, and pulse rate $180 /$ minute with sinus rhythm. The infant was semicomatose and moderately hypotonic.

Electrolyte estimation showed serum sodium 174 $\mathrm{mmol} / \mathrm{l}$, potassium $9.8 \mathrm{mmol} / \mathrm{l}$, and serum urea 240 $\mathrm{mg} / 100 \mathrm{ml}(40 \mathrm{mmol} / \mathrm{l})$. White cell count was $20 \times 10^{9} / 1$, with a polymorphonuclear leucocytosis. He was treated with plasma, hydrocortisone, $0.45 \%$ sodium chloride, bicarbonate, and antibiotics. Attempts were made to control the high serum potassium with glucose and insulin, an ion-exchange resin, and later peritoneal dialysis.

Received 23 May 1977
Three hours after admission the abdomen was noted to be swollen, with oedema of the abdominal wall and mottling of the lower limbs. During the first 8 hours only $3 \mathrm{ml}$ of cloudy urine was passed. 15 hours after admission convulsions occurred which were controlled but the infant died after a cardiac arrest.

At post-mortem an ante-mortem thrombus was found at the bifurcation of the aorta which extended down into the right itiac artery. At the site of insertion of the ductus into the aorta there was an adherent thrombus of longer standing, insinuating itself into the lumen of the aorta. There was no other abnormality except the presence of some pus in the middle ear.

Case 2. A male child born to a nondiabetic mother was first seen at the age of 14 days with diarrhoea. The history suggested that the stools had been loose since birth and the infant had been feeding poorly but had not vomited. On admission the infant was shocked, pale, and there was diffuse mottling of the body and grunting respirations. There was gross dehydration, the legs were cold, cyanosed, and flaccid, and no pulses were palpable. There was some erythema in the right hypochondrium.

Rehydration was carried out and the acidosis corrected with bicarbonate and $0.45 \%$ sodium chloride but a period of cardiac arrest occurred soon after admission and resuscitation was unsuccessful. At post-mortem there was a thrombus arising within the partially closed ductus and extending into the aorta (Fig). Again there was pus in the right middle ear.

Case 3. A male infant was admitted to hospital at the age of 10 days. He was a term infant and delivery had been uncomplicated. There had been a short illness of 2 days' duration with recurrent vomiting and the passage of 8-10 green watery stools in the 


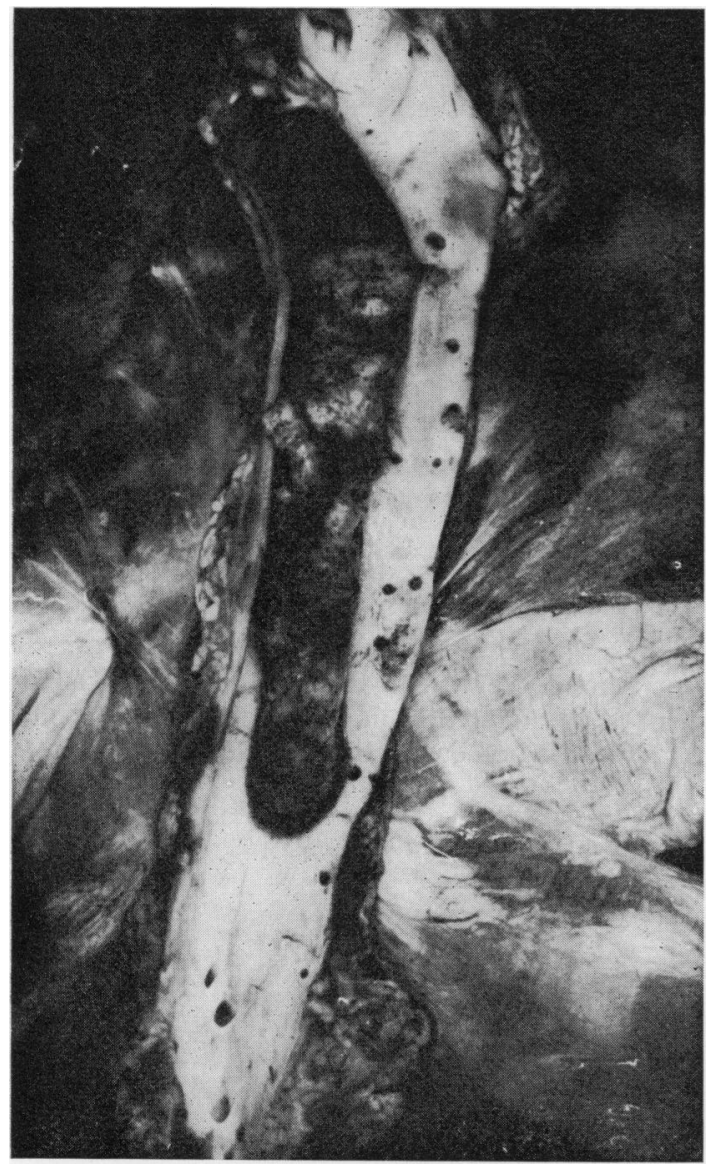

Fig. Showing the long thrombus extending down into the aorta from an origin in the ductus (top centre).

preceding 24 hours. Some of the stools had appeared bloodstained and immediately before admission the urine was bright red. Bruising had occurred on the right hand and right leg. There was no family history of serious illness or bruising. There was no history of diabetes.

On examination he was quiet, and had cyanosis of the legs and severe dehydration. Temperature was $38 \cdot 4^{\circ} \mathrm{C}$. Serum sodium was $163 \mathrm{mmol} / \mathrm{l}$ and blood urea $250 \mathrm{mg} / 100 \mathrm{ml}(41.6 \mathrm{mmol} / \mathrm{l})$. Urinalysis showed a heavy deposit of red cells. He was treated with hydrocortisone, colistin, and chloramphenicol, vitamin $\mathrm{K}$, and oral fluids. However, he died after cardiac arrest, within 24 hours of admission.

At post-mortem there was cyanosis of the lower extremities, purpuric lesions on the neck, and the fontanelle was depressed. The ductus was patent and there was aneurysmal dilatation which contained thrombus. A second thrombus was obstructing the bifurcation of the aorta at the iliac arteries. There was infarction of both kidneys.

\section{Discussion}

In 1941, Heller and Alvari reviewed the published reports on gangrene of the extremities in the newborn. They found 40 cases in all, 9 involving the upper extremity and 24 the lower extremity, and in 7 the involvement was more diffuse. They felt that their cases fell into two major groups; those in which the gangrene seemed related to pressure associated with long and difficult deliveries and those associated with infection. In other cases suggestions of Raynaud's disease, neurological disorders, and diabetes in the mother were based on less convincing evidence. However, the incidence of hard and difficult labour and neonatal asphyxia was in excess of that encountered in routine deliveries.

Gross (1945) added 6 of his own cases and noted that sepsis was an important factor but re-emphasised the observation of Klob (1859) that the ductus arteriosus was often involved in the process. In some cases he described 'extraordinary dilatation of the ductus arteriosus and thrombosis of this vessel'. $\mathrm{He}$ concluded that 'there seemed little doubt that the thrombus had originated as an embolus from the ductus arteriosus'. It was accepted that sepsis trauma during delivery and polycythaemia were factors, but emphasis was laid on the importance of the original thrombotic episode occurring within the ductus. Other earlier reports also implicate the ductus, particularly those of Kowalski (1921) whose case included renal artery thrombosis and Gruner (1904) who described thrombi in the coeliac artery.

More recently (Egan and Eitzman, 1971; Erkan et al., 1968; Neal et al., 1972; Gupta et al., 1968), attention has been paid to the introduction of indwelling catheters and the importance of the ductus appears to have been forgotten. The normal ductus closes functionally within 8-24 hours of birth. As the lungs expand on inspiration there is a rotation of the ductus which causes some narrowing. The final closure occurs later by hypertrophy of the intimal lining and extension of endothelial cushions developed in utero (Hislop and Reid, 1974), and it has been suggested that fluid is lost from the wall due to changes in sodium transport. Thrombosis should not occur in the normal ductus as it closes. Factors which may interrupt this normal sequence are a fall in the $\mathrm{PO}_{2}$ which causes ductal dilatation in sheep and in these circumstances thrombosis may occur in the lumen.

It is apparent from published reports that several factors lead to the production of thrombosis with 
emboli in the newborn. The major ones are dehydration, polycythaemia, sepsis, trauma, and in recent years the use of umbilical catheters. Whatever the cause of the formation of the thrombus it seems evident that the ductus may be implicated in more of the cases of peripheral arterial embolus described than is at present appreciated.

We thank Mrs R. Parkinson for help in preparing the manuscript.

\section{References}

Dohan, F. C. (1934). Gangrene of an extremity in a newborn infant with review of literature. Journal of Pediatrics, 5, 756-762.

Egan, E. A., II, and Eitzman, D. V. (1971). Umbilical vessel catheterization. American Journal of Diseases of Children, 121, 213-218.

Erkan, V., Blankenship, W., and Stahlman, M. T. (1968). The complications of chronic umbilical vessel catheterization. (Abst.) Pediatric Research, 2, 317.

Gross, R. E. (1945). Arterial embolism and thrombosis in infancy. American Journal of Diseases of Children, 70, 61-73.
Gruner, E. P. J. (1904). Ueber einen Fall von Aneurysma des Ductus arteriosus Botalli mit Parientalthrombus der Aorta. Speyer and Kaerner, Frieburg i. Breisgau.

Gupta, J. M., Robertson, N. R. C., and Wigglesworth, J. S. (1968). Umbilical artery catheterization in the newborn. Archives of Disease in Childhood, 43, 382-387.

Heller, G., and Alvari, G. (1941). Gangrene of the extremities in the newborn; occurrence of functional recovery. American Journal of Diseases of Children, 62, 133-140.

Hislop, A., and Reid, L. (1974). Growth and development of the respiratory system-anatomical development. Scientific Foundations of Paediatrics, 1st ed. p. 238. Ed. by J. A. Davis and J. Dobbing. Heinemann, London.

Klob, J. (1859). Thrombosis ductus Botalli. Zeitschrift der $k$. $k$. Gesellschaft der Aerzte zu Wien 15, 4.

Kowalski, W. (1921). Ueber Thrombose des Ductus arteriosus bei Neugeborenen. Virchows Archiv für Pathologische Anatomie und Physiologie und für Klinische Medizin, 233, 191-203.

Neal, W. A., Reynolds, J. W., Jarvis, C. W., and Williams, H. J. (1972). Umbilical artery catheterization; demonstration of arterial thrombosis by aortography. Pediatrics, 50, 6-13.

Correspondence to Dr G. T. Knowlson, Department of Pathology Birmingham Children's Hospital, Ladywood Middleway, Birmingham B16 8ET. 